\title{
Urgent endoscopy in children: epidemiology in a large region of France
}

\section{다 (용}

\author{
Authors \\ Pigneur $^{1}$, Jerome Viala ${ }^{4,7}$ \\ Institutions \\ 1 Pediatric Gastroenterology, Hepatology and Nutrition, \\ Necker Children's Hospital, Paris, France \\ 2 Pediatric Gastroenterology, Hepatology and Nutrition \\ Ospedale Papa Giovanni XXIII, Bergamo, Italy \\ 3 FROM Research Foundation, ASST Papa Giovanni XXIII, \\ Bergamo, Italy \\ 4 Pediatric Gastroenterology and Nutrition, Universitary \\ Robert-Debré hospital, Paris, France \\ 5 U1139 Pharmacology Department, Paris University, \\ Paris, France \\ 6 Pediatric Gastroenterology and Nutrition, Trousseau \\ Hospital, Paris, France \\ 7 Paris Denis-Diderot Faculty. Paris, France
}

Lorenzo Norsa ${ }^{1,2}$, Alberto Ferrari ${ }^{3}$, Alexis Mosca ${ }^{4}$, Cecile Talbotec ${ }^{1}$, Florence Campeotto ${ }^{1,5}$, Julie Lemale ${ }^{6}$, Bénédicte

submitted 10.12 .2019

accepted after revision 16.4 .2020

Bibliography

DOI https://doi.org/10.1055/a-1178-9408 |

Endoscopy International Open 2020; 08: E969-E973

(c) Georg Thieme Verlag KG Stuttgart · New York

elSSN 2196-9736

Corresponding author

Dr. Lorenzo Norsa, Piazza Oms 1, 24027 Bergamo, Italy

Fax: +390352674795

Inorsa@asst-pg23.it

\section{ABSTRACT}

Background and study aims The real burden of urgent endoscopy in children has not been studied yet. Our aim was to evaluate the need for urgent endoscopy in children. Patients and methods Information was collected about all the calls that were received during the 24 hour on-call shift for pediatric endoscopy in the region of Ile-de-France (12.1 million inhabitants) during a 6 months period (February-July 2017).

Results A total of 237 calls (19 calls/y/100,000 children) were collected regarding children of an average age of 3.2 years (range 2 days- 18 years). Most of the calls (68\%) were for foreign body ingestions. Gastroscopy was required in $32 \%$ of children: $24 \%$ of those calling for foreign body ingestion, $48 \%$ for gastrointestinal bleeding, $63 \%$ for caustic ingestions $(P=0.01)$. The average time between the call and the urgent endoscopy were below the international recommendations for each situation.

Conclusions Calling the endoscopist seems to have become a recurrent practice, although in most cases, urgent endoscopy did not appear necessary, especially for foreign body ingestion. This organization of pediatric endoscopy on call was able to guarantee the performance of urgent endoscopy in adequate timing for a highly populated region.

\section{Introduction}

Urgent endoscopy is part of the clinical practice of pediatric gastroenterology as reported in the guidelines for pediatric endoscopy of the European Society of Pediatric Gastroenterology Hepatology and Nutrition (ESPGHAN) [1]. The guidelines provide evidence on how endoscopists should manage urgent conditions such as foreign body ingestions and upper and lower gastrointestinal bleeding.

Despite this publication, the situation of urgent pediatric endoscopy in Europe and even worldwide is unclear and is based on different national realities. A recent survey of pedia- tric endoscopy in the UK pointed out that only $50 \%$ of tertiary centers for pediatric endoscopy could provide a valuable service to face upper Gl bleedings [2]. This important issue is exhaustively addressed in a recent review [3].

That having been said, it is very difficult to estimate the real incidence of need for urgent endoscopy. Literature on this topic is usually based either on single-center experience or focused on one of the indications for urgent pediatric endoscopy [46]. An important systematic review on foreign body ingestion in children pointed out difficulties in finding literature on this topic [7]. Even in literature on adult patients, a survey of emer- 
gency endoscopy in Canada showed large regional differences in the practice of after-hours endoscopy [8].

Data on the activity of pediatric endoscopists in Ile-deFrance were collected prospectively to determine epidemiology, needs and indications for urgent endoscopy in children living in a region with very high population density. The secondary aim was to evaluate the efficacy of this regional system by evaluating time from call to endoscopy performance.

\section{Patients and methods}

In France, pediatric on-call endoscopy is regionally organized. Ile-de-France is the most populated region in France and three pediatric gastroenterology departments are involved to guarantee the performance of urgent pediatric endoscopy at all times. This system for handling pediatric urgent endoscopy was first proposed in the 1990s and has been implemented over the last 20 years through constant collaboration between pediatric gastroenterologists in the region. In the French healthcare system, private clinics are not accredited to perform pediatric urgent endoscopy. Any physician from a regional hospital can call the on-call endoscopist from $6 \mathrm{p} . \mathrm{m}$. to $8 \mathrm{a} . \mathrm{m}$. weekdays and at any time during weekends and bank holidays, to report a suspect case. The case is described to the endoscopist, who then decides on the therapeutic strategy. No pediatric urgent endoscopic procedure can be performed without an indication from the pediatric on-call endoscopist. If an endoscopy is needed, the patient is transferred from the regional hospital to the gastroenterology department of the on-call endoscopist. All children transferred received endoscopy. In one hospital, some of foreign bodies in the proximal esophagus were removed in the Ear, Nose and Throat Department and were excluded from the study.

Between February 1 and July 31, 2017, all pediatric endoscopists $(n=8)$ involved in this rotation prospectively completed a case report form (CRF) for all calls received. The study period was selected as being representative of different seasons (winter, spring, summer) and including vacation periods in order to limit selection biases.

Data were collected by phone or personally when patients were admitted for urgent endoscopy: geographical origin, timing and reason of the call, age, sex, decision of the endoscopist (advise over the phone, patient transfer to the gastroenterology department or urgent endoscopy performance), outcome of endoscopy (foreign body extraction, varices ligations etc.).

The CRF included other information such as medical history and symptoms, which were not included in the current analysis because they not relevant to the aim of this study.

For epidemiological analysis, reference data on the French population in 2017 were used from the Institut National de la Statistique et des Étude Économiques (INSEE) [9]. The study was approved by the local ethical committee (CNIL: 2031554).

\section{Statistical analysis}

Statistical analysis was performed using IBM SPSS Statistics 21. Categorical data were summarized in absolute frequencies and percentages, globally and stratified by variables of interest (age

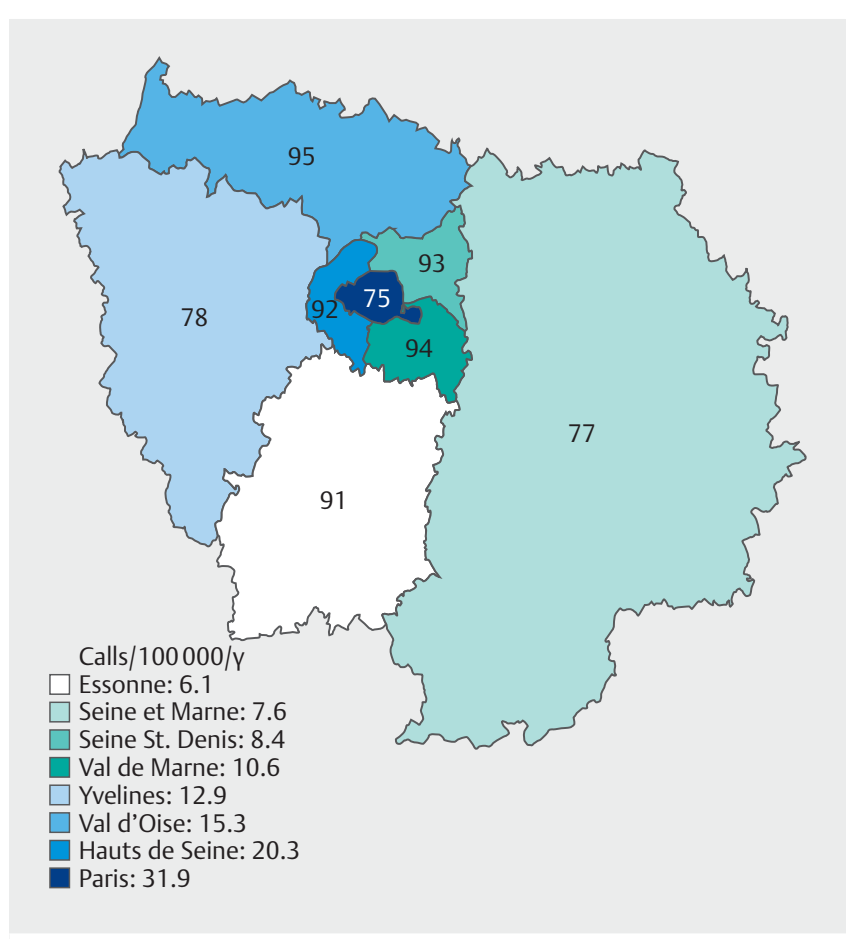

- Fig. 1 Incidence of urgent endoscopy calls divided by department of Ile-de-France region.

group, department). Call prevalence were presented as absolute counts and relative frequencies (calls/100,000/year) with $95 \%$ Poisson confidence intervals, globally and stratified by variables of interest. Quantitative variables were summarized with mean + SD and/or median (IQR), globally and stratified by variables of interest. Continuous variables were analyzed with the Anova One Way variance test or the non-parametric Kruskal-Wallis test and the t-test independent sample or MannWhitney's test. Kolmogorov-Smirnov test was used to assess Gaussian distribution of the data. Categorical variables were compared using Chi Square test and Multivariate analysis when appropriate.

\section{Results}

\section{Epidemiology of endoscopist calls}

During the 6 months of the study, 237 phone calls were registered. Of them, six came from hospitals outside the region covered by the service and six did not mention the origin hospital. In 2017, the Ile-de-France region counted a total population of $3,171,681$ inhabitants between 0 and 18 years old, for a total of 15 calls/100,000 (Cl $95 \%$ 12.7-16.6) children/year. Results by department are shown in $\mathbf{F i g .} \mathbf{1}$.

- Fig. 2 shows the distribution of calls according to age categories. Calls were more prevalent for younger children.

In total, the on-call endoscopist faced an average of 10 (5) calls/week with an average of 3 (4) endoscopy weekly. 


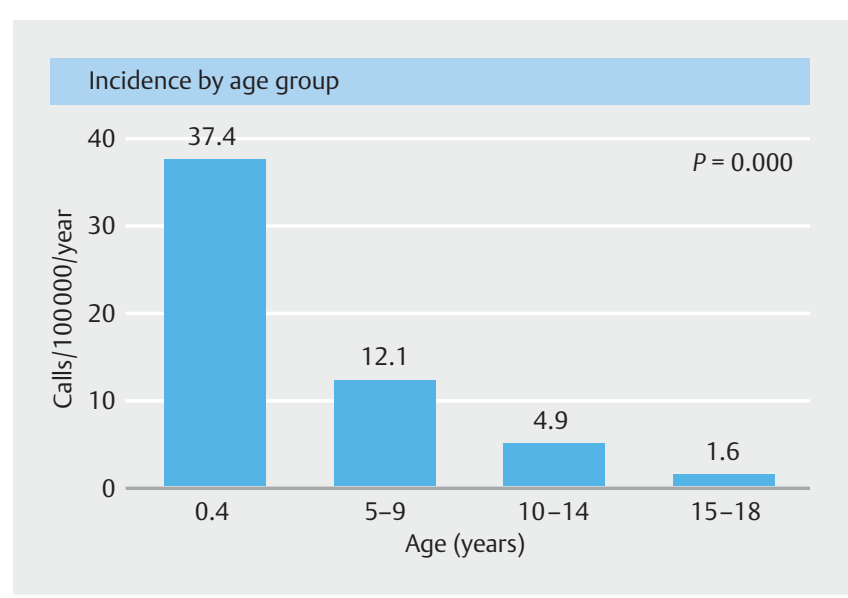

- Fig. 2 Incidence of calls according to age.

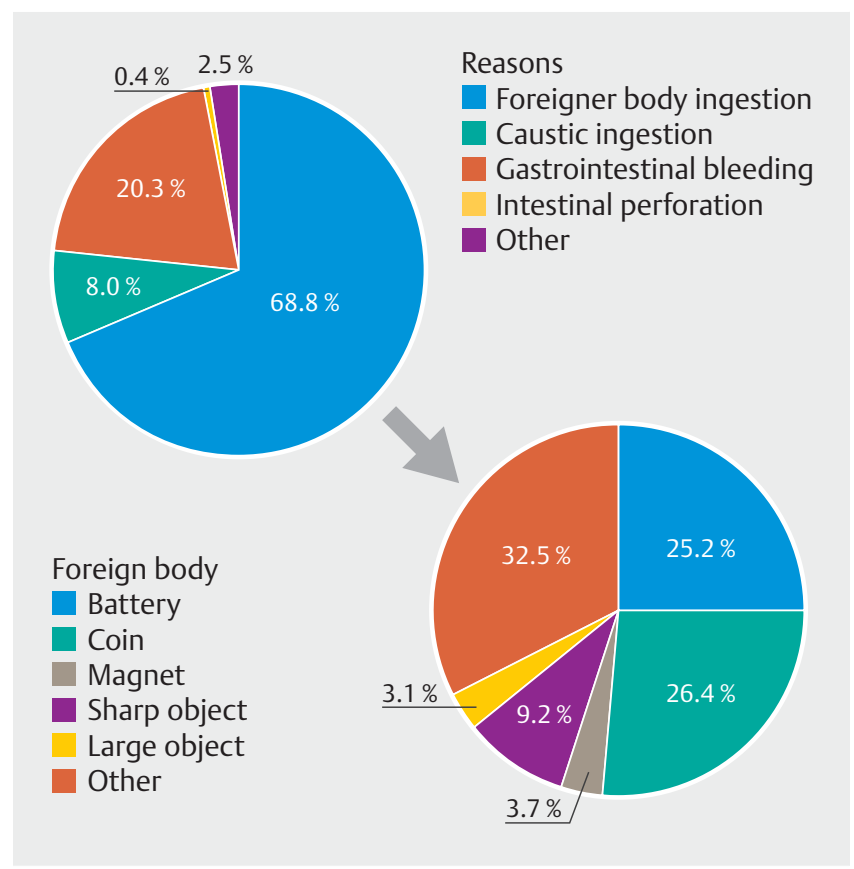

Fig. 3 Reasons for endoscopist calls.

\section{Reasons for endoscopist calls}

Reasons for endoscopist call are detailed in $\mathbf{F i g . 3}$. The most common reason for calls was foreign body ingestion (68\%).

When analyzing the reasons for endoscopist calls divided by department (Paris vs others departments), there were fewer calls foreign body ingestion ( $56 \%$ vs $74 \%$ ) and more for gastrointestinal bleeding ( $29 \%$ vs $17 \%$ ) from Paris $(P=0.04)$. Reasons for endoscopist call were similar in the different age groups.

\section{Outcomes of endoscopist calls}

Among the 237 calls, $32 \%$ of children required an urgent upper endoscopy and an additional colonoscopy was performed in seven children with gastrointestinal bleeding. The average age of children receiving endoscopy $(n=76)$ was 3 years (interquartile range 5). Of them, $52.6 \%$ had ingested a foreign body,
$30.3 \%$ has gastrointestinal bleeding, and $15.8 \%$ had caustic ingestion. Foreign body extraction was performed in $93 \%$ of upper endoscopies. In the remaining three procedures, no foreign body was found on endoscopy, meaning that it had probably already passed the pylorus. Urgent esophageal variceal band ligation was performed in $13 \%$ of patients for gastrointestinal bleeding and one esophageal dilation was performed for a food impaction in the upper esophagus ( $\triangleright$ Fig.4).

If we compare the absolute number of calls for which endoscopy ws performed, the need to perform an endoscopy was higher for caustic ingestion (63\%) than for gastrointestinal bleeding (48\%) or foreign body ingestion (24\%); $P=0.01$.

Endoscopies divided by department are detailed in $>$ Fig. $\mathbf{5}$. One endoscopy was performed in a child transferred from a hospital outside the region, and thus was excluded. Urgent endoscopy was performed more frequently for calls from Paris $(P=0.008)$ than compared to other departments. University hospitals, which are located in the Paris region, had a higher proportion of required endoscopies (48\%) compared with nonuniversity hospitals $(37 \%)(P=0.003)$.

\section{Timing of endoscopy}

Timing between call and endoscopy performance was a median of 3 hours (IQR: 9.4) for esophageal foreign body, 9 hours (18.5) for gastrointestinal bleeding, 10 hours (16.7) for foreign body in the stomach, and 16.2 hours (7.7) for caustic ingestion. In cases of esophageal foreign bodies, batteries were removed in five cases within 3 hours of the call, coins in 12 cases within a maximum of 18 hours, and one sharp object in 5 hours.

\section{Discussion}

Pediatrician from emergency rooms in lles-de-France call a pediatric endoscopist for advice 10 times a week. This means 15 calls for 100,0000 children a year. Calls mainly concern younger children and foreign body ingestion. An urgent endoscopy is required for approximately one-third of these children. When performed, endoscopy has a high rate of foreign body extraction while operative endoscopy for active upper gastrointestinal bleeding is rarely needed. Timing from the call to the endoscopy performance respects current guidelines for pediatric urgent endoscopy.

The real incidence of urgent endoscopist call and of urgent endoscopy performance for children was not previously reported in the literature, probably due to difficulty accessing data from large regions. Our study was able to find those results because the regional model of collaboration for urgent pediatric endoscopy was established more than 20 years ago in lle-deFrance, and thus, all pediatric emergency departments in the region are aware of its existence and rely on it.

Data on proportion of urgent endoscopy on total number of calls suggest that a large majority of cases have been managed by the endoscopist with only advice over the phone. A more capillary spreading of urgent endoscopy guidelines to pediatricians working in emergency rooms should be advised to limit unnecessary calls. This could be the subject of a future followup study. 


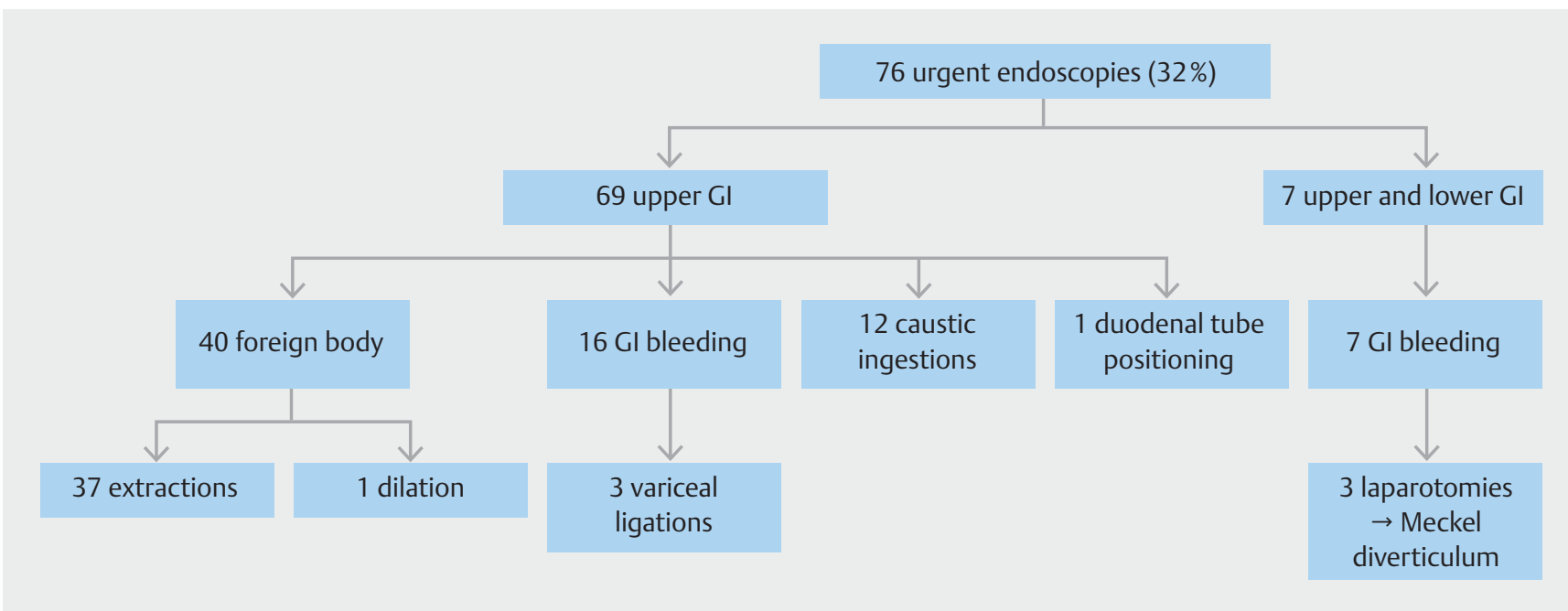

-Fig.4 Flowchart of endoscopies performed.

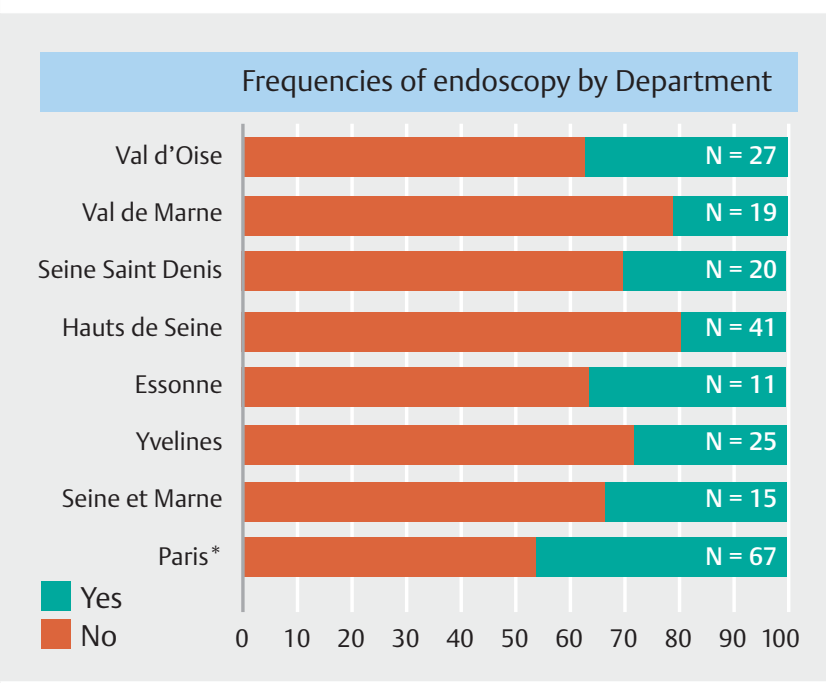

- Fig. 5 Need to perform an endoscopy according to department of call.

Despite lack of specific data on it, foreign body ingestion in younger children seems to be the most frequent reason for performing urgent endoscopy in children, as shown in a previous report. The latest report from the American Association of Poison Control [10] showed that foreign bodies were one of the most common ingested products with up to 70,000 cases/year in a population $<5$ years of age. As previously reported, coins and batteries are the most common ingested foreign bodies $[7,11,12]$. Furthermore, other commonly ingested products were cleaning substances, including caustic agents. More recently a very comprehensive data collection onall foreign body ingestions in American children was published and corroborated the belief that foreign body ingestion was increasingly prevalent [13]. The numbers presented in the US report are much higher than the prevalence shown in our survey, but unfortunately, data on the need for endoscopy are not reported. The percentage of calls for foreign body and caustic ingestions requiring urgent endoscopy are in line with large series found in literature [5, 14].

No specific data on the number of endoscopies performed for pediatric gastrointestinal bleeding are presented in the literature. A large American publication on pediatric gastrointestinal bleeding consultation reported that only $11.3 \%$ of children underwent hospitalization for further analysis [15]. This seems to be explained by the differences in the national health care system, because one of the risk factors independently associated with further hospitalization was availability of private health insurance in the American survey, and conversely, France offers a public health care system free of charge. However, it is important to underscore that in our study, despite the appropriate timing, only a very small proportion of patients needed urgent curative endoscopy for gastrointestinal bleeding.

The number of calls and urgent endoscopies performed was higher in the Paris department compared to other areas. This finding confirms independent risk factors in hospitalization for gastrointestinal bleeding are presence of three or more comorbidities and access to a university teaching hospital [15].The three third-level teaching pediatric hospitals in Ile-de-France are located in Paris and are the ones that provide follow-up for complex children.

The recently published guidelines from ESPGHAN on endoscopy [15] suggest that timing of urgent endoscopy performance be determined based on the urgency of the case. In particular, as reported in literature, batteries in the esophagus are the most emergent indication because of possible serious complications [16], as well as sharp objects in the esophagus, while coins in the esophagus can be removed in the first 12 hours. Batteries in the stomach can be removed in the first 24 hours in asymptomatic children, while other objects can be followed up without endoscopy, unless they are very large or the children are symptopmatic. The indirect correlation between reliability of endoscopy for upper gastrointestinal bleeding and timing is well known from adult studies [17], thus the indication is 
to perform it in the first 12 hours after bleeding. On the other hand, to achieve more reliable staging of esophageal damage, endoscopy should be performed between 12 and 24 hours after caustic ingestion. Despite a surface coverage of $12,000 \mathrm{~km}^{2}$, the proposed collaborative multicenter model succeeded in providing urgent endoscopy within suggested timeframes for all patients enrolled.

To date, no data have been published on the amount of work done by on-call pediatric endoscopists. With a median of 10 calls and three endoscopies weekly, this model of centralization seems to be sustainable if shared by an appropriate number of endoscopist, which could be achieved only with collaboration of more experienced centers.

The strength of this paper was the well-trained model of collaboration among three large pediatric endoscopy units. Thus, the results are reliable and complete, giving some good epidemiological data.

One limitation is that battery ingestion may have been underestimated. In our clinical practice, it may be possible for endoscopists in small hospitals or ENT specialists to rapidly remove batteries in the uppermost part of the esophagus. For this reason, those data are not included in our series. However, in our study, the few batteries retained in the esophagus were removed in timely fashion.

Furthermore, because of the primary epidemiological aim, we did not collect information on outcomes of patients after endoscopy.

\section{Conclusion}

In conclusion we demonstrated the reliability of a regional collaborative work capable of fulfilling the need for urgent pediatric endoscopy in highly populated regions.

\section{Competing interests}

The authors declare that they have no conflict of interest.

\section{References}

[1] Thomson M, Tringali A, Dumonceau J-M et al. Paediatric Gastrointestinal Endoscopy: European Society for Paediatric Gastroenterology Hepatology and Nutrition and European Society of Gastrointestinal Endoscopy Guidelines. J Pediatr Gastroenterol Nutr 2017; 64: 133153
[2] Henderson P, Hansen R, Russell R et al. PTH-061 The management of acute upper gastrointestinal bleeding in paediatric practice: a national survey. Gut 2014; 63: A235.2-A236

[3] Thomson M. There is no excuse for mortality due to lack of competency and training of paediatric endoscopists in gastrointestinal bleeding therapy in 2018. J Pediatr Gastroenterol Nutr 2018; 67: 684688

[4] Denney W, Ahmad N, Dillard B et al. Children will eat the strangest things: a 10-year retrospective analysis of foreign body and caustic ingestions from a single academic center. Pediatr Emerg Care 2012; 28: 731-734

[5] Betalli P, Falchetti D, Giuliani S et al. Caustic Ingestion Italian Study Group. Caustic ingestion in children: Is endoscopy always indicated? The results of an Italian multicenter observational study Gastrointest Endosc 2008; 68: 434-439

[6] Banc-Husu AM, Ahmad NA, Chandrasekhara V et al. Therapeutic endoscopy for the control of nonvariceal upper gastrointestinal bleeding in children: a case series. J Pediatr Gastroenterol Nutr 2017; 64: e88-e91

[7] Jayachandra S, Eslick GD. A systematic review of paediatric foreign body ingestion: presentation, complications, and management. Int J Pediatr Otorhinolaryngol 2013; 77: 311-317

[8] Muthiah KC, Enns R, Armstrong D et al. A survey of the practice of after-hours and emergency endoscopy in Canada. Can J Gastroenterol J Can Gastroenterol 2012; 26: 871-876

[9] Population totale par sexe et âge au 1er janvier 2019, France - Bilan démographique 2018. Insee; https://www.insee.fr/fr/statistiques/ 1892086 ? sommaire $=1912926$

[10] Gummin DD, Mowry JB, Spyker DA et al. 2016 Annual Report of the American Association of Poison Control Centers' National Poison Data System (NPDS): 34th Annual Report. Clin Toxicol Phila Pa 2017; 55: 1072-1252

[11] Litovitz T, Whitaker N, Clark L et al. Emerging battery-ingestion hazard: clinical implications. Pediatrics 2010; 125: 1168-1177

[12] Lee JH. Foreign body ingestion in children. Clin Endosc 2018; 51: 129136

[13] Orsagh-Yentis D, McAdams RJ, Roberts KJ et al. Foreign-Body ingestions of young children treated in US emergency departments: 19952015. Pediatrics 2019; 143: doi:10.1542/peds.2018-1988

[14] Al Lawati TT, Al Marhoobi R. Patterns and complications of ingested foreign bodies in Omani children. Oman Med J 2018; 33: 463-467

[15] Pant C, Olyaee M, Sferra T] et al. Emergency department visits for gastrointestinal bleeding in children: results from the Nationwide Emergency Department Sample 2006-2011. Curr Med Res Opin 2015; 31: 347-351

[16] Krom H, Visser M, Hulst JM et al. Serious complications after button battery ingestion in children. Eur J Pediatr 2018; 177: 1063-1070

[17] Spiegel BM, Vakil NB, Ofman JJ. Endoscopy for acute nonvariceal upper gastrointestinal tract hemorrhage: Is sooner better? A systematic review Arch Intern Med 2001; 161: 1393-1404 